\title{
What can a dental nurse do?
}

\author{
The General Dental Council's (GDC's) Scope of practice guidance for \\ registered dental nurses.
}

\section{Introduction}

The General Dental Council (GDC) updated their Scope of practice guidance document in December 2020 (it was originally effective from 30 September 2013). ${ }^{1}$ In 2020 the GDC undertook research to understand how the guidance is used, what the impacts of the guidance have been, and to decide on its future. New guidance is planned for the end of 2021 - we will update readers in 2022 once this is announced and available.

\section{What is scope of practice?}

The scope of your practice is a way of describing what you are trained and competent to do. It describes the areas in which you have the knowledge, skills and experience to practise safely and effectively in the best interests of patients.

This guidance sets out the skills and abilities dental nurses should have. It is not a list of tasks that someone can do. The guidance also describes additional skills that you might develop after registration to increase your scope of practice.

You must practise in accordance with the GDC's Standards for the dental team ${ }^{2}$ at all times. To carry out the additional skills you need to undertake further training.

\section{Dental nurses}

Dental nurses are registered dental professionals who provide clinical and other support to registrants and patients. As a dental nurse, you can undertake the following if you are trained, competent and indemnified:

- Prepare and maintain the clinical environment, including the equipment

- Carry out infection prevention and control procedures to prevent physical, chemical and microbiological contamination in the surgery or laboratory

- Record dental charting and oral tissue assessment carried out by other registrants

- Prepare, mix and handle dental bio-materials

- Provide chairside support to the operator during treatment

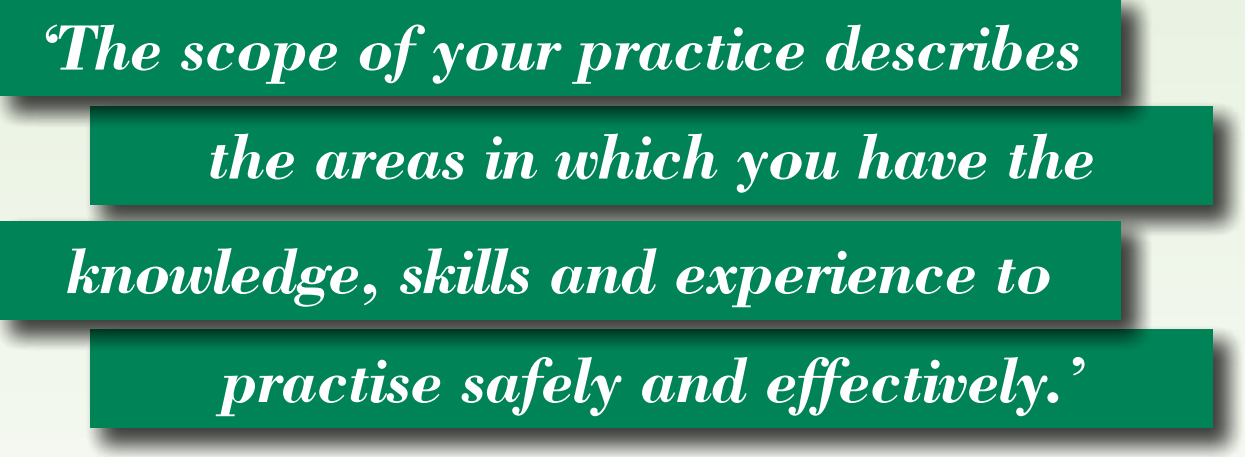

- Keep full, accurate and contemporaneous patient records

- Prepare equipment, materials and patients for dental radiography

- Process dental radiographs

- Monitor, support and reassure patients

- Give appropriate patient advice

- Support the patient and their colleagues if there is a medical emergency

- Make appropriate referrals to other health professionals.

\section{Additional skills}

Additional skills dental nurses could develop include:

- Further skills in oral health education and oral health promotion

- Assisting in the treatment of patients who are under conscious sedation

- Further skills in assisting in the treatment of patients with special needs

- Further skills in assisting in the treatment of orthodontic patients

- Intra and extra-oral photography

- Pouring, casting and trimming study models

- Shade taking

- Tracing cephalographs.

\section{Additional skills carried out on}

prescription from, or under the direction of, another registrant:

- Taking radiographs

- Placing rubber dam

- Measuring and recording plaque indices

- Removing sutures after the wound has been checked by a dentist

- Constructing occlusal registration rims and special trays

- Repairing the acrylic component of removable appliances

- Applying topical anaesthetic to the prescription of a dentist

- Constructing mouthguards and bleaching trays to the prescription of a dentist

- Constructing vacuum formed retainers to the prescription of a dentist

- Taking impressions to the prescription of a dentist or a clinical dental technician (CDT) (where appropriate).

Dental nurses can apply fluoride varnish either on prescription from a dentist or direct as part of a structured dental health programme. Dental nurses do not diagnose disease or treatment plan. All other skills are reserved to one or more of the other registrant groups.

\section{References}

1. General Dental Council. Scope of practice. Effective from September 2013. Updated December 2020. Available at: https:// www.gdc-uk.org/information-standardsguidance/standards-and-guidance/scopeof-practice (accessed October 2021).

2. General Dental Council. Standards for the dental team. Effective from September 2013. Updated June 2019. Available at: https://www.gdc-uk.org/informationstandards-guidance/standards-andguidance/standards-for-the-dental-team (accessed October 2021).

https://doi.org/10.1038/s41407-021-0764-z 